Journal of Clinical Investigation

vol. 42, No. 2, 1963

\title{
AMINO ACID EXTRACTION AND AMMONIA METABOLISM BY THE HUMAN KIDNEY DURING THE PROLONGED ADMINISTRATION OF AMMONIUM CHLORIDE *
}

\author{
By EDWARD E. OWEN AND ROSCOE R. ROBINSON \\ (From the Department of Medicine, Duke University Mcdical Center, and the Veterans Ad- \\ ministration Hospital, Durham, N. C.)
}

(Submitted for publication June 25, 1962; accepted November 1, 1962)

According to current concepts, renal ammonia synthesis may be attributed to the renal extraction and catabolism of certain plasma amino acids. In 1943, Van Slyke and associates demonstrated in the dog that the amide nitrogen of glutamine was removed from arterial plasma in quantities sufficient to account for approximately 60 per cent of the urinary ammonia excreted during metabolic acidosis (1). It was proposed that the remaining 40 per cent of urinary ammonia could be accounted for by the renal uptake of plasma $\alpha$-amino nitrogen. In agreement with this hypothesis, many investigators have since shown that the administration of several amino acids other than glutamine is associated with an increased urinary ammonia excretion (2-4). Loading experiments of this type have indicated thatbesides glutamine-glycine, alanine, asparagine, leucine. and histidine may serve as precursors of urine ammonia. The demonstration of appropriate enzyme systems within renal tissue capable of forming ammonia from these substrates has been offered as additional support for the thesis that several plasma amino acids may participate normally in the renal production of ammonia. Nevertheless, the specific amino acids that serve as renal ammonia precursors have not been identified clearly in conditions associated with normal acid-base balance and normal plasma amino acid concentrations. The present study was undertaken for two principal reasons: first, to characterize the typical patterns of uptake or release

* Investigation supported in part by U. S. Public Health Service research grants A-5930 and A-6306 from the National Institutes of Health, Bethesda, Md., and by the Veterans Administration Clinical Investigator Program; presented in part at the annual meeting of the Southern Section, Amer. Fed. Clin. Research, New Orleans, La., January 18, 1962. of individual amino acids by the normal human kidney, and second, to determine whether or not the adaptive increase of renal ammonia production during metabolic acidosis could be attributed to changes in the renal extraction of certain plasma amino acids.

\section{METHODS}

Twelve renal clearance experiments were carried out on eleven healthy male volunteers between 21 and 38 years old. All studies were conducted with them in the recumbent position after an overnight fast. To facilitate the collection of timed urine specimens, urine flows of approximately $5 \mathrm{ml}$ per minute were assured by the oral ingestion of $500 \mathrm{ml}$ of tap water 1 hour before the test, followed immediately by a constant intravenous infusion of 5 per cent dextrose in water. After appropriate priming doses, an intravenous maintainance infusion of a solution of inulin and para-aminohippurate (PAH) was begun 45 minutes before the first clearance period via a Bowman constant-infusion pump. During the equilibration period, a no. 7 or 8 cardiac catheter was introduced into a renal vein through either the right brachial or femoral vein under fluoroscopic control. An indwelling Cournand arterial needle was placed in the left brachial artery. Three sequential clearance periods, each 20 to 40 minutes long, were obtained during all experiments. Simultaneous arterial and renal venous blood samples were drawn for analysis at the approximate midpoint of each urine collection period. Urine was collected without the aid of bladder catheterization by voiding into a flask containing a small amount of mineral oil.

Six of the 12 experiments were performed during the presence of a mild metabolic acidosis induced by the daily oral ingestion of 6 to $8 \mathrm{~g}$ of nonenteric coated ammonium chloride for 6 to 9 days before the procedure. The first clearance period was obtained 8 to 12 hours after administration of the last dose of ammonium chloride. In one subject, G.J., experiments were performed both before and after the prolonged administration of ammonium chloride.

The free amino acid content of urine and arterial and renal venous plasma was determined by the ion exchange column chromatographic technique of Spackman, Stein, 
and Moore (5) with a Beckman Spinco model 120 amino acid analyzer. With the exception of glutamine, an accuracy of \pm 3 per cent was obtained regularly with this procedure when 0.1 to $0.3 \mu$ mole of an amino acid was placed on the column for analysis. The total quantity of most free amino acids placed on the columns fell within this range when plasma and urine samples were prepared for analysis by the following procedures.

Plasma. Protein precipitation was carried out immediately after collection by the addition of $50 \mathrm{ml}$ of 1 per cent picric acid to $10 \mathrm{ml}$ of plasma. After centrifugation, excess picrate was removed from the supernatant fluid by filtration of a $50-\mathrm{ml}$ sample through a $2 \times 2-\mathrm{cm}$ column bed of Dowex $2 \times 8$ resin. The column bed was then washed with $15 \mathrm{ml}$ of $0.02 \mathrm{~N} \mathrm{HCl}$, and the total eluate was lyophilized and reconstituted in $4.2 \mathrm{ml}$ of citrate buffer at $\mathrm{pH}$ 2.2. These samples were stored at $-20^{\circ} \mathrm{C}$ until analysis, when $2-\mathrm{ml}$ samples were placed on the columns.

Since glutamine cannot be separated reliably from asparagine under the usual conditions of chromatography (6), arterial and renal venous plasma concentrations of glutamine were also measured by an enzymatic assay technique using a specific glutaminase obtained from $E$. coli, strain W. The enzyme was prepared according to Meister, Levintow, Greenfield, and Abendschein (7) and the glutamine assay was carried out in duplicate as described by Segal and Wyngaarden (8). Duplicate determinations agreed within \pm 8 per cent and recoveries of glutamine added to plasma ranged between 94 and 106 per cent consistently. Plasma glutamine values obtained by enzymatic assay were between 20 and 30 per cent higher than the glutamine-asparagine concentrations measured by column chromatography.

Urine. The $\mathrm{pH}$ of $10-\mathrm{ml}$ samples of urine was adjusted to between 11.5 and 12 by the drop-by-drop addition of $4 \mathrm{~N} \mathrm{NaOH}$. After 6 hours of vacuum desiccation, the urine samples were acidified to $\mathrm{pH} 2.0$ to 2.2 with $6 \mathrm{~N} \mathrm{HCl}$ and their volume readjusted to $10 \mathrm{ml}$ by the addition of citrate buffer at $\mathrm{pH}$ 2.2. The samples were then stored at $-20^{\circ} \mathrm{C}$ until analysis. The appropriate sample volume to be placed on the column for free amino acid analysis was calculated by the method of Stein (9).

Blood and urine ammonia was measured by a modification of the microdiffusion method of Brown, Duda, Korkes, and Handler (10). Inulin was determined by the resorcinol method of Roe as modified by Schreiner (11). $\mathrm{PAH}$ was measured by the technique of Selkurt (12). The $\mathrm{pH}$ of whole blood and urine was determined with a Cambridge model $\mathrm{R}$ pH-meter equipped with an enclosed glass electrode. Measurements were made at room temperautre and were corrected to $37^{\circ} \mathrm{C}$ with Rosenthal's factor (13). The total $\mathrm{CO}_{2}$ content of arterial blood was determined by the method of Van Slyke and Neill (14). Assuming a $\mathrm{pK}$ of 6.11 , the plasma $\mathrm{CO}_{2}$ tension was calculated from the line chart of Van Slyke and Sendroy (15). Oxygen content and saturation of arterial blood were determined by the spectrophoto- metric method of Hickam and Frayser (16). The hematocrit of arterial blood was measured in duplicate by the method of Wintrobe (17).

Calculations. Glomerular filtration rate was measured by the clearance of inulin. True or total renal plasma flow was estimated from the clearance and extraction of $\mathrm{PAH}$. Total renal blood flow was calculated from this value and the peripheral arterial hematocrit (18).

Estimates of the net uptake or release of each free amino acid across the renal circulation were obtained by multiplying the arteriorenal venous amino acid difference by total renal plasma flow. Because urinary amino acid excretion rates were not measured in all studies, these values were not used in the calculation of net renal uptake or release. Because of their small magnitude, however, their use in such calculations would not have affected materially the directional patterns of uptake or release that were obtained from the use of $\mathrm{A}-\mathrm{V}$ differences alone. The total amino acid nitrogen values used in similar balance calculations reflect the summation of the nitrogen content of each amino acid measured by column chromatography.

Renal venous ammonia release was calculated from the $\mathrm{A}-\mathrm{V}$ difference of ammonia and the total renal blood flow. The total bidirectional release of ammonia was obtained by summing the values for urine ammonia excretion and renal venous ammonia release.

\section{RESULTS}

Experiments in healthy human subjects without prior administration of ammonium chloride. For all clearance periods in these 6 experiments, glomerular filtration rate and total renal blood flow averaged 157 and $1,491 \mathrm{ml}$ per minute, respectively. Extraction ratios for $\mathrm{PAH}$ remained steady throughout each procedure and averaged $88 \pm 5$ per cent. The plasma bicarbonate concentration averaged $25.5 \pm 1.3$ mmoles per $\mathrm{L}$, plasma $\mathrm{pCO}_{2}$ was $46 \pm 3.9 \mathrm{~mm} \mathrm{Hg}$, and arterial $\mathrm{pH}$, $7.35 \pm .02$ units. A modest decrease of arterial $\mathrm{pH}$ and elevation of arterial $\mathrm{pCO}_{2}$ was observed in one subject, but could be attributed to the presence of mild pulmonary hypoventilation induced by sleep. Urine $\mathrm{pH}$ remained constant in each subject and averaged $5.98 \pm .33$ for the entire group.

Table I lists the individual values of each of the 6 patients for renal blood flow, urine $\mathrm{pH}$, ammonia release into urine and renal venous blood, and the arterial and renal venous concentrations of ammonia and those amino acids whose net extraction or release appeared of definite magnitude. In addition, the average arterial plasma concentrations of all 19 free amino acids are summarized for the entire group in Table II; with the appropriate 


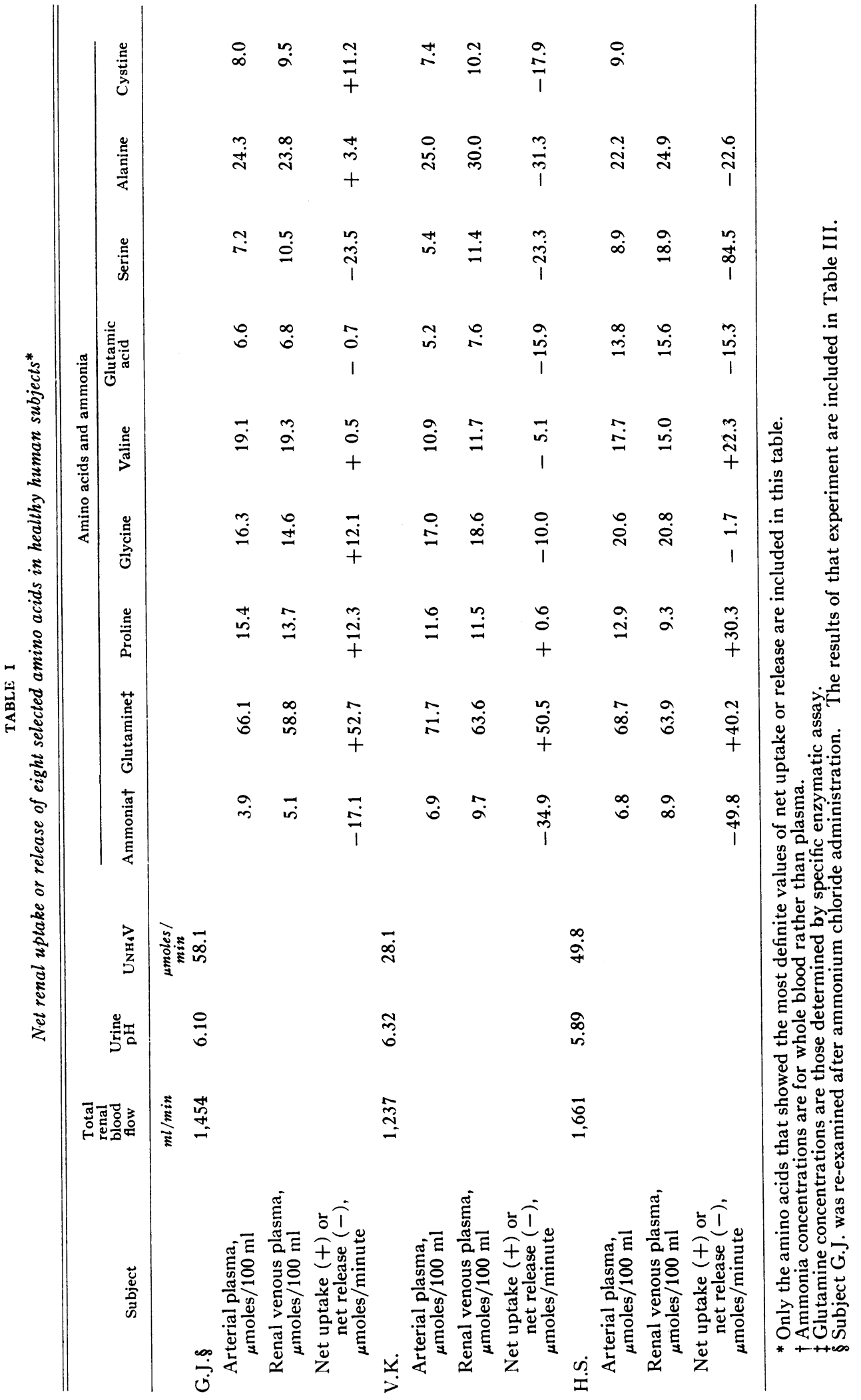


EDWARD E. OWEN AND ROSCOE R. ROBINSON

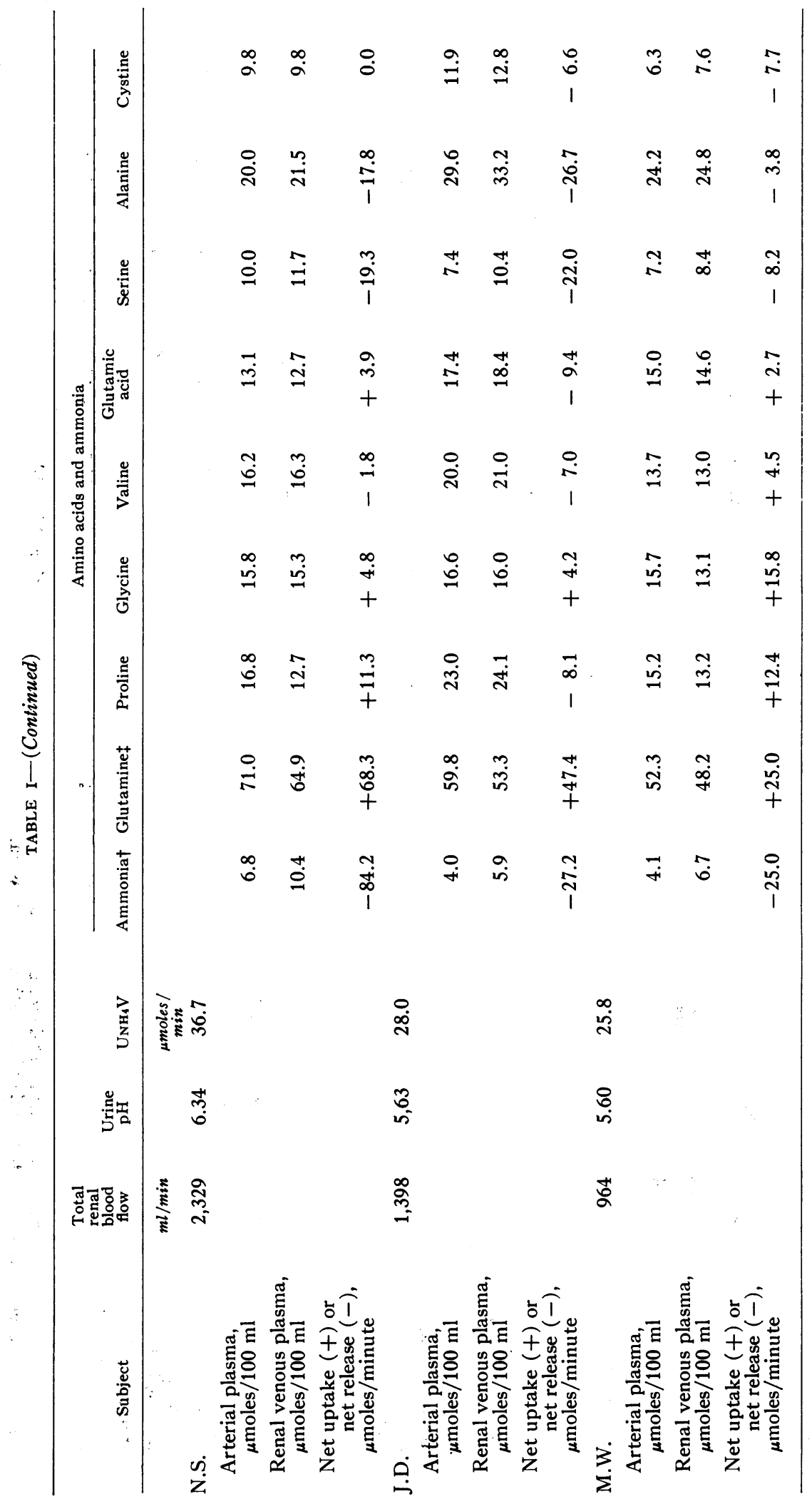


average values for either their net renal uptake or release. In these studies, urine ammonia excretion averaged $37.8 \pm 25.6 \mu$ moles per minute, renal venous ammonia release was $37.3 \pm 24.6$ $\mu$ moles per minute, total renal ammonia release, $77.4 \pm 28 \mu$ moles per minute, the arterial blood ammonia concentration, $5.2 \pm 1.6 \mu$ moles per 100 $\mathrm{ml}$, and the venous blood ammonia level averaged $7.8 \pm 2.2 \mu$ moles per $100 \mathrm{ml}$.

Of those amino acids-glutamine, proline, and glycine-that exhibited the most definite figures of net uptake from plasma by the kidney (Tables I and II), only glutamine was extracted consistently by all 6 subjects. Net glutamine uptake averaged $47 \pm 14 \mu$ moles per minute for the entire group. Net renal extraction of proline occurred in 5 of 6 studies, and glycine exhibited net uptake in 4 of 6 experiments (Table I). Although valine also demonstrated net extraction during most experiments, the average net uptake of this amino acid was much less than that of either glutamine, proline, or glycine (Table II).

Serine, glutamic acid, alanine, cystine, and arginine comprised the group of amino acids that clearly exhibited average values for net release into renal venous plasma (Tables I and II). Of

TABLE II

Net renal uptake or release of free amino acids in healthy human subjects*

\begin{tabular}{|c|c|c|c|c|}
\hline \multirow[b]{2}{*}{ Amino acids } & \multicolumn{2}{|c|}{$\begin{array}{l}\text { Arterial plasma } \\
\text { concentration }\end{array}$} & \multicolumn{2}{|c|}{$\begin{array}{l}\text { Net uptake }(+) \text { or } \\
\text { net release }(-)\end{array}$} \\
\hline & Average & Range & Average & Range \\
\hline & \multicolumn{2}{|c|}{ Amoles $/ 100 \mathrm{ml}$} & \multicolumn{2}{|c|}{ umoles/minute } \\
\hline Taurine & 6.1 & $4.8-8.7$ & +2.5 & +15.2 to -5.7 \\
\hline Threonine & 10.6 & $8.0-13.3$ & -0.1 & +9.0 to -7.2 \\
\hline Serine & 8.8 & $7.2-10.1$ & -30.1 & -8.2 to -84.5 \\
\hline Glutamine† & 64.9 & $52.3-71.0$ & +47.4 & +68.0 to +25.0 \\
\hline Proline & 17.4 & $11.6-24.8$ & +9.8 & +30.3 to -8.1 \\
\hline Glutamic & 12.4 & $5.2-17.4$ & -5.8 & +3.9 to -15.9 \\
\hline Glycine & 18.4 & $15.7-24.5$ & +4.2 & +15.8 to -10.0 \\
\hline Alanine & 26.1 & $20.0-35.6$ & -16.5 & +3.4 to -31.3 \\
\hline Valine & 18.2 & $10.9-30.6$ & +2.2 & +22.3 to -7.0 \\
\hline Half-cystine & 8.4 & $5.8-11.9$ & -10.8 & 0.0 to -17.9 \\
\hline Methionine & 1.4 & $1.1-2.5$ & +0.4 & +5.0 to -3.5 \\
\hline Isoleucine & 4.3 & $1.7-8.6$ & +2.0 & +4.0 to -0.8 \\
\hline Leucine & 7.9 & $4.6-12.9$ & -2.4 & +4.5 to -6.0 \\
\hline Tyrosine & 3.3 & $2.0-4.8$ & -4.0 & +0.4 to -11.1 \\
\hline Phenylalanine & 3.6 & $2.8-4.8$ & -0.2 & +3.4 to -6.5 \\
\hline Ornithine & 4.9 & $3.2-6.9$ & -0.8 & +0.2 to -1.8 \\
\hline Lysine & 10.4 & $10.3-10.6$ & -2.0 & +1.3 to -5.4 \\
\hline Histidine & 6.8 & $6.1-7.2$ & 0.0 & +4.0 to -3.6 \\
\hline Arginine & 6.4 & $4.4-8.6$ & -6.0 & +1.8 to -16.1 \\
\hline
\end{tabular}

* Net uptake or release was calculated by multiplying each arteriorenal venous amino acid difference by total renal plasma flow.

$\dagger$ Values listed for glutamine were obtained from enzymatic analysis rather than from column chromatography. these, only serine was added to renal venous blood by all subjects (Table I), and usually in considerable quantity, averaging $30 \pm 27 \mu$ moles per minute. Net venous release of the other amino acids in this group was noted in at least 4 of 6 experiments, and in some instances (alanine and cystine), their addition to venous plasma was of respectable proportions (Tables I and II). Glutamic acid also exhibited net release in 4 of 6 studies, averaging $5.8 \mu$ moles per minute for all subjects. Although leucine and tyrosine were usually added to renal venous plasma, the average values for their net release were smaller than those of either serine, glutamic acid, alanine, cystine, or arginine (Table II).

The arteriorenal venous differences of the remaining amino acids-taurine, threonine, methionine, isoleucine, phenylalanine, ornithine, lysine, and histidine-were so small or variable that no conclusions could be drawn as to the presence of either net uptake or net release (Table II).

Total ammonia nitrogen release by the kidneys during these experiments averaged $1.05 \pm 0.36$ mg per minute (Table V). Of this amount, 49.5 per cent $(0.52 \pm 0.34 \mathrm{mg}$ per minute) was released into renal venous blood and the remaining 50.5 per cent, $(0.53 \pm 0.18 \mathrm{mg}$ per minute) was excreted in urine. Despite the addition of more free amino acids to renal venous plasma than were extracted from arterial plasma, the net balance of total amino acid nitrogen across the renal circulation was positive (net uptake) in 5 of 6 subjects, averaging $0.53 \pm 0.59 \mathrm{mg}$ per minute for the entire group. From these data it is apparent that the total renal release of ammonia nitrogen cannot be accounted for solely by an analysis of the net renal extraction of total amino acid nitrogen from plasma. Similarly, the average net uptake of glycine and the amide nitrogen of glutamine $(0.72 \pm$ $0.22 \mathrm{mg}$ per minute) could account for only 70 per cent of the total renal ammonia nitrogen release. The average net extraction of glycine and glutamine total nitrogen $(1.39 \pm 0.41 \mathrm{mg}$ per minute), however, was more than sufficient (132 per cent) to provide the total amount of ammonia nitrogen released by the kidney. In fact, the renal extraction of glutamine total nitrogen $(1.33 \pm$ $0.41 \mathrm{mg}$ per minute) was the major determinant of the modest positivity (net uptake) of total amino acid nitrogen extraction observed in these 
EDWARD E. OWEN AND ROSCOE R. ROBINSON

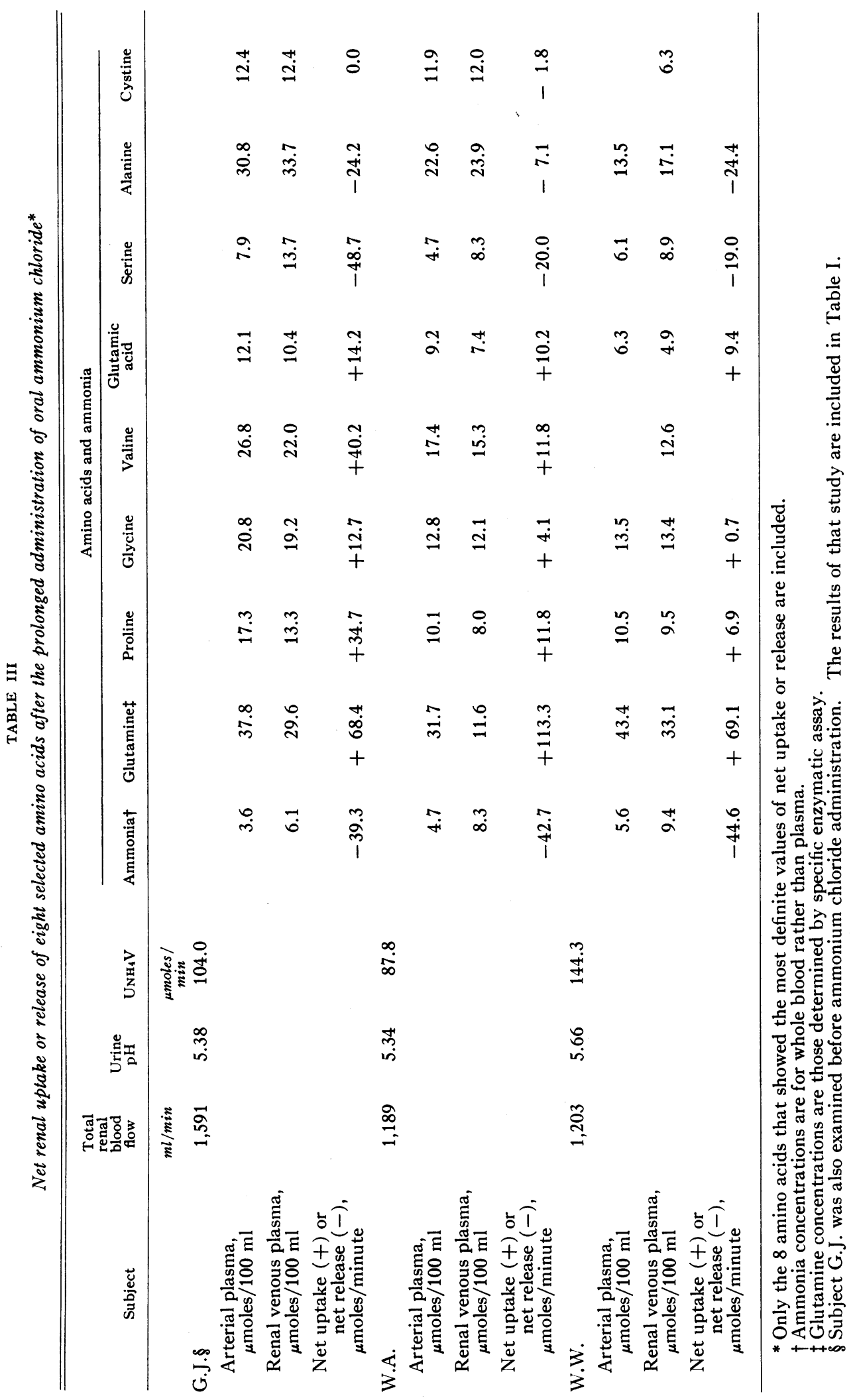




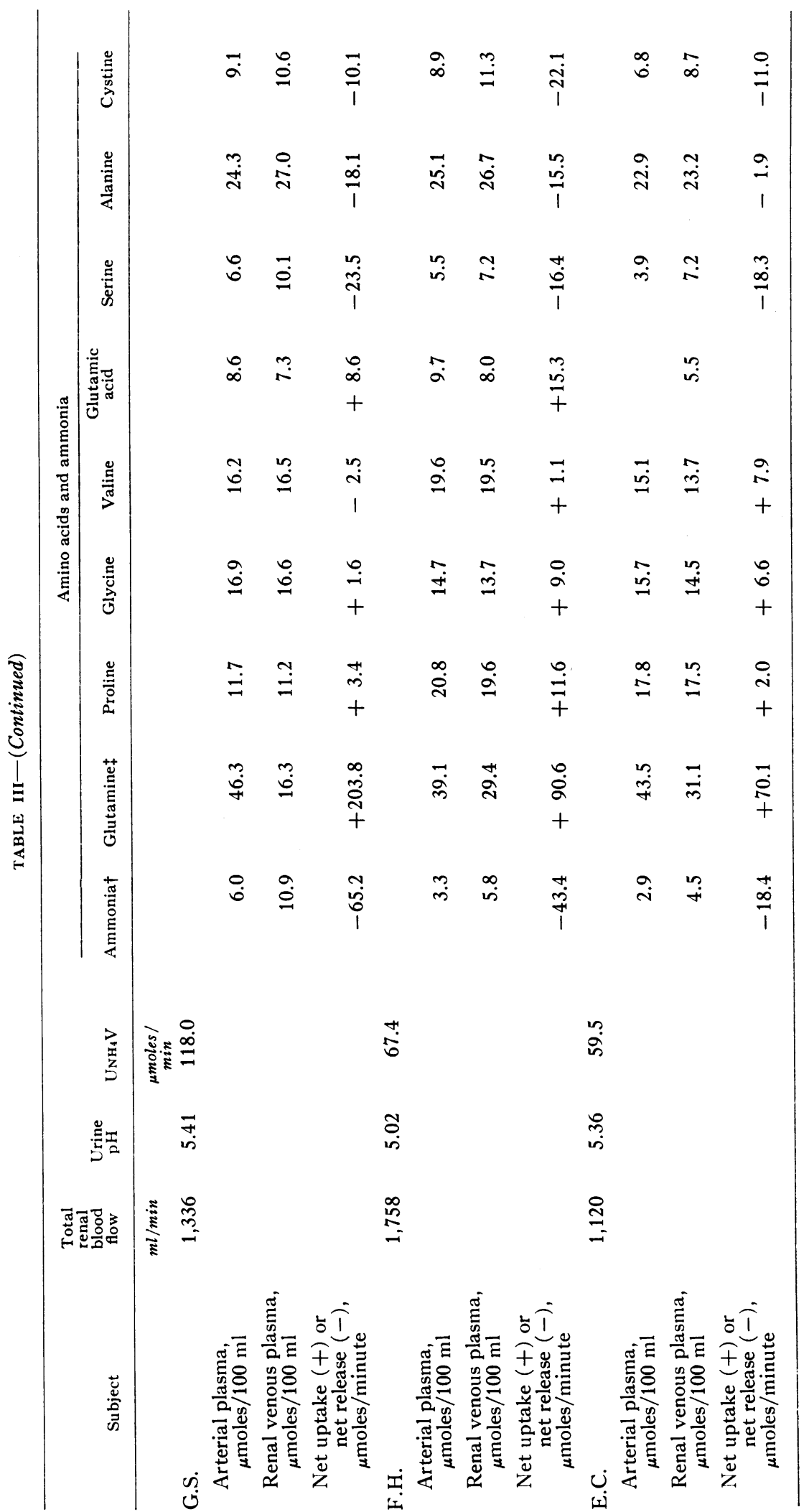


subjects. If glutamine total nitrogen was excluded from this calculation, an average net addition of total amino acid nitrogen to renal venous blood occurred that averaged $0.80 \pm .61 \mathrm{mg}$ per minute.

It should be emphasized that the amino acid nitrogen balances listed above were obtained only across the renal circulation. They do not represent total balance calculations, since urinary amino acid excretion rates were not included. Although urine amino acid excretion was measured in two subjects, the values were normal and their inclusion in the calculations would not have appreciably altered the individual amino acid balances (net uptake or release) across the renal circulation.

Experiments in healthy human subjects during mild ammonium chloride acidosis. Values for glomerular filtration rate and total renal blood flow were within accepted normal limits during all six studies. Filtration rate averaged $125 \mathrm{ml}$ per minute and total renal blood flow $1,366 \mathrm{ml}$ per minute. $\mathrm{PAH}$ extraction ratios were almost identical to those of the nonammonium chloride subjects and remained constant throughout each individual study. Plasma bicarbonate concentrations averaged $22 \pm 2$ mmoles per $\mathrm{L}$, arterial $\mathrm{pCO}_{2}, 39 \pm$ $5 \mathrm{~mm} \mathrm{Hg}$, and arterial blood $\mathrm{pH}, 7.33 \pm 0.05$. Urine $\mathrm{pH}$ was stable throughout each experiment, averaging $5.36 \pm 0.20$ for the entire group.

The individual values of renal blood flow, urine $\mathrm{pH}$, renal venous ammonia release, urine ammonia excretion, and the arterial and renal venous concentrations of ammonia and certain amino acids are listed in Table III for each subject. As before, the group averages for the arterial plasma concentration, urine excretion rate, and net uptake or release of all 19 amino acids are summarized in Table IV. As anticipated, the prolonged administration of ammonium chloride was associated with a higher average value for total renal ammonia release $(139.1 \pm 42 \mu$ moles per minute) than was observed in those subjects who did not ingest the drug. In these subjects, the arterial blood ammonia averaged $4.4 \pm 1.3 \mu$ moles per $100 \mathrm{ml}$, the renal venous ammonia concentration, $7.5 \pm 2.4 \mu$ moles per $100 \mathrm{ml}$, and the urine ammonia excretion, $96.8 \pm 31.9 \mu$ moles per

TABLE IV

Net renal uptake or release and urinary excretion of free amino acids in healthy human subjects after prolonged oral ingestion of ammonium chloride*

\begin{tabular}{|c|c|c|c|c|c|c|}
\hline \multirow[b]{2}{*}{ Amino acids } & \multicolumn{2}{|c|}{ Arterial plasma conc. } & \multicolumn{2}{|c|}{ Net uptake $(+)$ or net release $(-)$} & \multicolumn{2}{|c|}{ Urinary excretion $\dagger$} \\
\hline & Average & Range & Average & Range & Average & Range \\
\hline & \multicolumn{2}{|c|}{ umoles $/ 100 \mathrm{ml}$} & \multicolumn{2}{|c|}{ umoles/minute } & \multicolumn{2}{|c|}{ $\mu m o l e s / m i n u t e$} \\
\hline Taurine & 6.4 & $3.7-10.4$ & $+\quad 4.2$ & +13.3 to -2.9 & 1.63 & $0.98-2.49$ \\
\hline Threonine & 7.8 & $6.0-11.4$ & $\begin{array}{r}1 \\
+\quad 0.1\end{array}$ & $+\quad 5.4$ to -5.2 & 0.13 & $0.10-0.15$ \\
\hline Serine & 5.8 & $3.9-7.9$ & -24.3 & -16.4 to -48.6 & 0.22 & $0.16-0.31$ \\
\hline Glutaminef & 40.3 & $31.7-46.3$ & +102.5 & +203.8 to +70.1 & 0.37 & $0.26-0.73$ \\
\hline Proline & 14.7 & $10.0-20.8$ & +11.5 & +33.6 to +2.0 & Trace & \\
\hline Glutamic & 9.2 & $6.3-12.1$ & +11.5 & +15.3 to +8.6 & Trace & \\
\hline Glycine & 15.7 & $12.8-20.8$ & $\begin{array}{r}5.8 \\
+\quad 5.8\end{array}$ & +12.7 to +0.7 & 0.63 & $0.27-1.19$ \\
\hline Alanine & 23.2 & $13.5-30.8$ & -15.2 & $-\quad 1.9$ to -24.4 & 0.24 & $0.15-0.37$ \\
\hline Valine & 19.0 & $15.1-26.8$ & +11.7 & +40.1 to -2.5 & 0.09 & $0.03-0.14$ \\
\hline Half-cystine & 10.3 & $6.8-14.4$ & $-\quad 9.0$ & $-\quad 0.2$ to -22.1 & 0.21 & $0.15-0.27$ \\
\hline Methionine & 1.3 & $1.0-1.6$ & $-\quad 0.1$ & $+\quad 1.8$ to -0.9 & Trace & \\
\hline Isoleucine & 3.6 & $2.8-5.1$ & $+\quad 0.1$ & $+\quad 1.0$ to -1.4 & Trace & \\
\hline Leucine & 7.6 & $4.4-12.2$ & $\begin{array}{l}+ \\
+\quad 0.2\end{array}$ & 4.0 to -2.9 & 0.04 & $\mathrm{Tr}-0.08$ \\
\hline Tyrosine & 3.7 & $2.6-4.6$ & $+\quad 0.2$ & 4.6 to -3.1 & 0.11 & $0.06-0.13$ \\
\hline Phenylalanine & 3.7 & $3.1-5.1$ & 0 & 1.5 to -1.0 & 0.08 & $0.03-0.11$ \\
\hline Ornithine & 5.2 & $4.1-6.1$ & 2.7 & +7.3 to -1.6 & Trace & \\
\hline Lysine & 12.9 & $11.8-14.4$ & 4.6 & +24.7 to -7.3 & 0.29 & $0.07-0.64$ \\
\hline Histidine & 5.9 & $5.1-7.5$ & +2.5 & +8.6 to -4.2 & 0.55 & $0.34-1.23$ \\
\hline Arginine & 4.9 & $3.2-6.4$ & -5.2 & $-\quad 2.4$ to -12.3 & Trace & \\
\hline
\end{tabular}

* Net renal uptake and release were calculated from A-V differences multipled by the total renal plasma flow.

$\dagger$ Measurable amounts of 1-methyl and 3-methyl histidine, $\alpha$-aminobutyric, phosphoethanolamine, and ethanolamine were present in urine and accounted for an average 20 per cent of total amino acid nitrogen excretion. They have not been listed because of the lack of corresponding plasma values.

$\ddagger$ Plasma values were measured by enzymatic assay. Urine values were determined by chromatography and represent the sum total of glutamine and asparagine concentrations, most of it asparagine. 


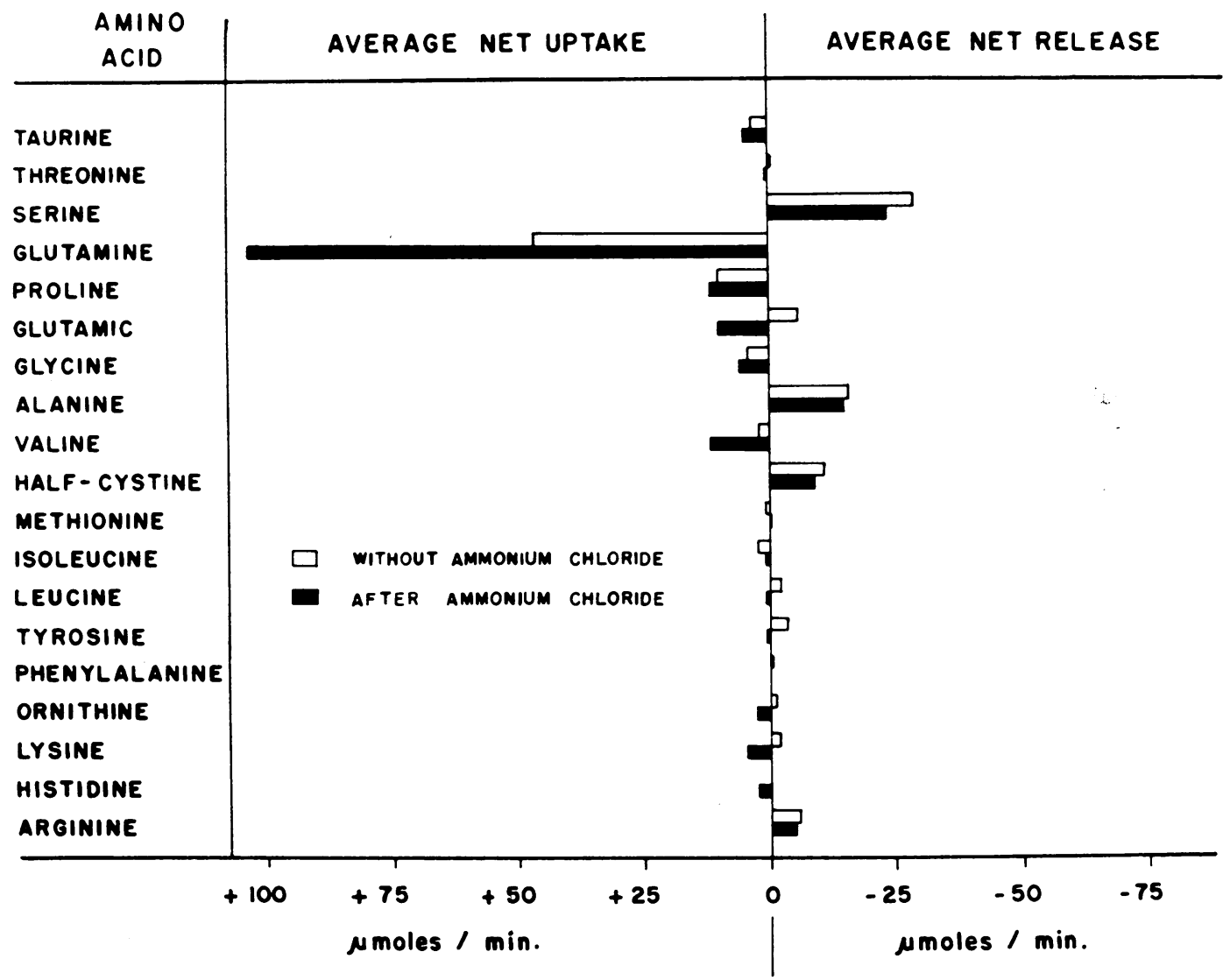

Fig. 1. Changes of Net Renal uptake or Release of Amino ACids induCed by Ammonium chloride ADMINISTRATION.

minute. Since the renal venous release of ammonia was essentially the same both before and after ammonium chloride administration $(37.3 \pm$ 24.6 and $42.3 \pm 14.9$ moles per minute, respectively) the elevated total ammonia release during mild acidosis appeared to be largely related to an increased urinary excretion of ammonia. This rise was highly significant statistically $(\mathrm{p}<0.01)$, and could not be explained satisfactorily by the relatively small reduction of urine $\mathrm{pH}$ that occurred after ammonium chloride administration (Table III).

Values from both experimental groups for the average net uptake or release of each amino acid have been illustrated in Figure 1 for purposes of graphic comparison. Ammonium chloride administration was unassociated with a significant change in the plasma levels of the various amino acids (Tables III and IV), with the exception of glutamine. In general, plasma amino acid con- centrations were similar to those of the nonammonium chloride group (Tables II and IV) and agreed closely with the values reported by Stein and Moore for peripheral venous plasma (6). During mild acidosis, however, the arterial plasma glutamine concentration averaged $40 \pm 5 \mu$ moles per $100 \mathrm{ml}$, a value significantly lower $(\mathrm{p}<0.01)$ than the $65 \pm 7.5 \mu$ moles per $100 \mathrm{ml}$ obtained in the nonammonium chloride group. A significant difference $(p<0.05)$ was also noted in the net renal extraction of glutamine from arterial plasma (Figure 1). During mild acidosis, glutamine extraction averaged $102 \pm 53 \mu$ moles per minute (Table IV), in contrast to $47 \pm 14 \mu$ moles per minute (Table II) in those subjects who did not receive ammonium chloride. As before, a similar percentage of the total renal release of ammonia could be accounted for by the renal extraction of glutamine amide nitrogen (74 per cent). As in the subjects who did not receive ammonium 
TABLE V

Changes of net renal uptake or release of ammonia and amino acid nitrogen associated with the prolonged administration of ammonium chloride

\begin{tabular}{|c|c|c|c|}
\hline \multicolumn{2}{|c|}{ Determination } & $\begin{array}{c}\begin{array}{c}\text { Without } \\
\text { ammonium } \\
\text { chloride }\end{array} \\
\mathrm{mg} / \mathrm{min}\end{array}$ & $\begin{array}{c}\begin{array}{c}\text { After } \\
\text { ammonium } \\
\text { chloride }\end{array} \\
\mathrm{mg} / \mathrm{min}\end{array}$ \\
\hline $\begin{array}{l}\text { Average renal release of ammonia } \\
\text { nitrogen }\end{array}$ & $\begin{array}{l}\text { Renal venous release } \\
\text { Urine excretion } \\
\text { Total renal release }\end{array}$ & $\begin{array}{c}m g / m i n \\
0.52 \\
0.53 \\
1.05\end{array}$ & $\begin{array}{c}m g / m i n \\
0.59 \\
1.36 \\
1.95\end{array}$ \\
\hline $\begin{array}{l}\text { Average net renal uptake of total } \\
\text { amino acid nitrogen* }\end{array}$ & & 0.53 & 2.86 \\
\hline $\begin{array}{l}\text { Average net renal uptake of } \\
\text { glutamine nitrogen }\end{array}$ & $\begin{array}{l}\text { Glutamine total nitrogen } \\
\text { Glutamine amide nitrogen }\end{array}$ & $\begin{array}{l}1.32 \\
0.66\end{array}$ & $\begin{array}{l}2.88 \\
1.44\end{array}$ \\
\hline $\begin{array}{l}\text { Average net renal release of amino } \\
\text { (glutamine total nitrogen exclud }\end{array}$ & $\operatorname{sen}$ & 0.79 & 0.02 \\
\hline
\end{tabular}

* The total nitrogen content of glutamine was used in this caluclation.

chloride, however, the net uptake of glutamine amide nitrogen could account for all of the ammonia excreted in urine.

Although after ammonium chloride the net renal uptake of proline, glycine, and valine averaged $12 \pm 4,6 \pm 5$, and $12 \pm 17 \mu$ moles per minute, respectively, these somewhat higher extraction values were not significantly different from those of the nonacidotic subjects (Figure 1). In contrast, however, ammonium chloride administration was associated with a highly significant $(p<0.01)$ directional change in the net balance of glutamic acid across the renal circulation (Figure 1). An average net release $(6 \pm 9 \mu$ moles per minute) of glutamic acid was observed in the nonammonium chloride group (Table II). During acidosis, however, glutamic acid was extracted (net uptake) consistently $(12 \pm 3 \mu$ moles per minute) from arterial plasma by the kidney. Average figures for the net uptake or release of the remaining amino acids were essentially the same in both experimental groups (Figure 1).

The average net balances of total amino acid and ammonia nitrogen across the renal circulation from both experimental groups have been compared in Table V. After ammonium chloride, the average net uptake of total amino acid nitrogen $(2.86 \pm 1.38 \mathrm{mg}$ per minute) was significantly higher $(p<0.01)$ than that observed in the absence of drug administration $(0.53 \pm 0.59$ $\mathrm{mg}$ per minute), and was more than sufficient (147 per cent) to account for the total renal release of ammonia nitrogen $(1.95 \pm 0.60 \mathrm{mg}$ per minute). As shown in Figure 1, higher extrac- tion values of the total nitrogen content of glutamine and glutamic acid were largely responsible for this increased uptake of total amino acid nitrogen.

\section{DISCUSSION}

Previous measurements in nonacidotic dogs have suggested that arteriorenal venous differences of total free amino acid nitrogen are so small and variable that no conclusion may be formed as to the presence of either net renal uptake or release (19). The present observations demonstrate that such differences are also small across the human kidney (Table V). However, the consistent finding of values indicative of net renal extraction suggests that these small differences may well be significant. Regardless of the validity of small arteriorenal venous differences of total free amino acid nitrogen, the present results indicate clearly that several free amino acids exhibit definite patterns of either net renal uptake or release that are not apparent from determinations of total free amino acid nitrogen alone. Characteristically, the healthy human kidney extracts glutamine, proline, glycine, and valine from arterial plasma, whereas serine, glutamic acid, cystine, leucine, and arginine are usually added to renal venous blood. Glutamine is the only free amino acid extracted consistently by the kidney from arterial plasma, and serine is the only amino acid regularly released into renal venous blood.

The precise metabolic activities of the kidney that are responsible for either the net uptake or 
release of certain amino acids are not identified by the present experiments. Nevertheless, quantitative differences between the net extraction or release of individual amino acids during conditions of normal acid-base balance and mild metabolic acidosis do permit certain statements to be made regarding the relationship of renal amino acid metabolism to ammonia production. It has been widely accepted for some time that the amide nitrogen of glutamine is the major precursor of urine ammonia. In addition, previous loading experiments have indicated that glycine, alanine, leucine, histidine, and asparagine may also serve as presursor materials for the renal production of ammonia $(2-4)$. Since glutamine and glycine were the only members of this group that exhibited net extraction by the kidney, the present results can definitely implicate only two of these six amino acids as possible ammonia precursors at normal plasma amino acid levels. Net asparagine utilization, however, has not been excluded with certainty since the analytic technique used in this study prohibited its accurate measurement (6).

Under normal conditions of acid-base balance, the net renal uptake of glutamine amide nitrogen was sufficient to account for 63 per cent of the total amount of ammonia nitrogen released by the kidneys. The net extraction of glycine nitrogen was adequate to provide an additional 6 per cent of the total bidirectional release of ammonia. The net removal rates of other amino acids implicated as ammonia precursors were insufficient to account for the remaining total release of ammonia.

The remaining 30 per cent of the ammonia added to urine, or renal venous blood, or both, may be accounted for by consideration of the possible fates of the glutamic acid arising from the enzymatic deamidation of glutamine by glutaminase. This process yields one mole of both glutamic acid and ammonia from each mole of available glutamine. If the $\alpha$-amino nitrogen of the glutamic acid produced by this reaction is not used in either ammonia synthesis or other metabolic reactions, a stoichiometric relationship between glutamine uptake and glutamic acid release should be found. That such is not the case is illustrated by the finding that only small amounts of free glutamic acid are actually released into either urine or renal venous blood. Although the present studies do not provide a definitive explanation of its fate, several possibilities must be considered. First, glutamic acid may contribute directly to renal ammonia production via its direct deamination to $\alpha$-ketoglutarate and ammonia by glutamic dehydrogenase. Second, it may participate in various transamination reactions leading to the production of other amino acids which, in turn, are either released unchanged into renal venous blood, or deaminated directly to form ammonia and the appropriate keto-acid. A metabolic pathway of this type provides one possible explanation for the net venous release of such amino acids as alanine and serine. Third, it may be released into either blood or urine in a conjugated form undetected by the chromatographic technique used in this study. Fourth, it may be used directly in the synthesis of various peptides or proteins by kidney tissue. Although the results of these experiments are compatible with a proposal that both the $\alpha$-amino and amide nitrogens of glutamine may serve as potential sources of renal ammonia, it is felt that complete utilization of glutamic acid for this purpose is unlikely for two principal reasons. First, the observed bidirectional release of ammonia is significantly less than would be expected if the $\alpha$-amino and amide nitrogens of glutamine were both used completely for its synthesis. Second, previous balance studies during the administration of glutamic acid have suggested that this amino acid does not contribute significantly to renal ammonia production $(2,3)$. Nevertheless, the possibility does exist that at least a portion of the glutamic acid arising from glutamine deamidation is used in the formation of ammonia. It is obvious that further experiments are needed to clarify the exact role of glutamic acid in the renal synthesis of ammonia.

Although the possible transamination reactions of the glutamic acid derived from glutamine provide a potential source of the amino acids added to renal venous blood, another possibility should be mentioned. If current estimates of the normal protein content of glomerular filtrate are valid, the intratubular digestion of reabsorbed protein could also contribute to the observed patterns of net amino acid release. If so, however, only a small amount of reabsorbed protein must be degraded completely in view of the small quantity of nitrogen actually added to renal venous blood 
as free amino acids. In addition, the dissimilarity between the amino acid composition of plasma proteins and the character of the free amino acids released into renal venous blood suggests that the degradation of reabsorbed protein by proteolytic enzyme systems is not solely responsible for their release.

The twofold adaptive rise of total renal ammonia production after ammonium chloride administration is in agreement with many previous observations $(20,21)$. Since renal venous ammonia release did not rise appreciably, this response was almost solely related to an increased urine excretion of ammonia. This observation raises the important question of whether or not the factors controlling renal venous ammonia release also participate in the adaptive response to ammonium chloride administration. Additional studies are urgently required to evaluate this possibility more fully.

After prolonged ammonium chloride administration, glutamine, valine, and glutamic acid were extracted by the kidney in increased amounts. Of these, only the increased net removal values of glutamine and glutamic acid were statistically significant, and only glutamine has been shown by previous loading experiments to be associated with an increased excretion of urine ammonia. Other amino acids such as glycine that have been suggested as renal ammonia precursors were not extracted in increased amounts. As under normal conditions of acid-base balance, most ( 74 per cent) of the total bidirectional release of ammonia could be explained by the increased extraction of glutamine amide nitrogen. Again, the data failed to account for approximately 25 per cent of the total ammonia released, unless the assumption is made that some, but not all, of the glutamic acid arising from glutamine deamidation is used in renal ammonia synthesis. The lower plasma glutamine concentration observed after ammonium chloride in association with an elevated renal extraction of glutamine has not been described previously. Its occurrence suggests, but does not prove, that the increased extraction of glutamine by the kidney is not counterbalanced by a compensatory rise in its availability to plasma.

Recently, the characteristic patterns of net renal uptake or release of free amino acids have been described in acidotic dogs by Shalhoub and asso- ciates (22). In most respects, their results appear to agree qualitatively with those observed during ammonium chloride administration to human subjects. They differ mainly in that mild metabolic acidosis in the human subject is associated with net renal extraction of glutamic acid rather than net release into renal venous plasma. The appearance of net glutamic acid uptake by the human kidney after ammonium chloride administration is difficult to relate to changes of renal ammonia metabolism unless, as discussed previously, one assumes either its direct deamination to ammonia and $\alpha$-ketoglutarate, or its transamination to other amino acids that may then serve as direct precursors of renal ammonia nitrogen. That such may be the case is perhaps implied by the fact that glutamine and glutamic acid are the only amino acids whose renal extraction was significantly responsive to an induced change of acidbase balance.

Although these experiments provide information that must be explained by any complete and final description of the mechanisms of renal ammonia metabolism and excretion, it is apparent that the exact sources of urinary ammonia nitrogen cannot be ascertained by the simultaneous measurement of urinary amino acid excretion and arteriorenal venous amino acid differences. In this regard, it should be emphasized that net balance data reflect only the algebraic summation of the rates of total organ influx and efflux of a given substance. After ammonium chloride administration, it is conceivable that an amino acid might be extracted in amounts sufficient for ammonia synthesis without an apparent change of net extraction if its increased total influx is, for whatever reason, also accompanied by an appropriate change of total organ efflux. Nevertheless, if the factors responsible for the total efflux of amino acids into renal venous blood remain constant after ammonium chloride administration, a contribution of any amino acid to increased ammonia production should be reflected by either diminished net release or increased net uptake. In the present experiments, the only significant changes of this type were those exhibited by glutamine and glutamic acid.

\section{SUM MARY}

1. The net renal uptake or release of 19 free amino acids and the total bidirectional release of 
ammonia (urinary excretion plus renal venous release) were measured in 6 healthy subjects under conditions of normal acid-base balance. Typically, serine, glutamic acid, alanine, cystine, and arginine were added to renal venous blood, whereas glutamine, proline, valine, and glycine usually exhibited net uptake. Only glutamine was extracted consistently by all subjects, and serine alone was added regularly to renal venous blood. The quantitative net release of glutamic acid was much less than the theoretical amount expected from the complete deamidation of extracted glutamine.

2. The net extraction of glutamine amide nitrogen accounted for only 63 per cent of the total bidirectional release of ammonia nitrogen. Other amino acids that have been implicated as renal ammonia precursors were not extracted in amounts sufficient to account for the remaining total ammonia release. If, however, the glutamic acid arising from glutamine deamidation is partially utilized for ammonia synthesis, then sufficient nitrogen is available from extracted amino acids to account for the observed total ammonia release.

3. Six similar experiments were performed after prolonged administration of ammonium chloride in an attempt to relate changes of renal amino acid extraction to the adaptive rise of renal ammonia production. With the exception of glutamine and glutamic acid, values for the net uptake or release of individual free amino acids resembled those of the subjects who did not receive ammonium chloride. Net glutamine uptake was significantly higher, and its amide nitrogen was extracted in amounts sufficient to account for 74 per cent of the increased total renal release of ammonia. The increased extraction of glutamic acid from plasma was small and insufficient to account for the remaining total release of ammonia. Again, however, total renal ammonia release could be satisfactorily explained by assuming that both nitrogens of extracted glutamine are potentially available to ammonia synthesis.

4. These data are compatible with the thesis that glutamine serves as the major precursor of renal ammonia under conditions of both normal acid-base balance and mild ammonium chloride acidosis, and that the glutamic acid arising from glutamine deamidation may also serve as a potential source of renal ammonia. They also imply that other amino acids do not contribute appreciably to renal ammonia production at normal plasma amino acid levels.

\section{ACKNOWLEDGMENT}

The authors express their indebtedness to Dr. Ronald C. Greene, Department of Biochemistry, Duke University Medical Center, for aid and advice in the performance of the amino acid analyses.

\section{REFERENCES}

1. Van Slyke, D. D., Phillips, R. A., Hamilton, P. B., Archibald, R. M., Futcher, P. H., and Hiller, A. Glutamine as source material of urinary ammonia. J. biol. Chem. 1943, 150, 481.

2. Lotspeich, W. D., and Pitts, R. F. The role of amino acids in the renal tubular secretion of ammonia. J. biol. Chem. 1947, 168, 611.

3. Kamin, H., and Handler, P. The metabolism of parenterally administered amino acids: III. Ammonia formation. J. biol. Chem. 1951, 193, 873.

4. Madison, L. L., and Seldin, D. W. Ammonia excretion and renal enzymatic adaptation in human subjects, as disclosed by administration of precursor amino acids. J. clin. Invest. 1958, 37, 1615.

5. Spackman, D. H., Stein, W. H., and Moore, S. Automatic recording apparatus for use in the chromatography of amino acids. Anal. Chem. 1958, 30, 1190.

6. Stein, W. H., and Moore, S. The free amino acids of human blood plasma. J. biol. Chem. 1954, 211, 915.

7. Meister, A., Levintow, L., Greenfield, R. E., and Abendschein, P. A. Hydrolysis and transfer reactions catalyzed by $\omega$-amidase preparations. J. biol. Chem. 1955, 215, 441.

8. Segal, S., and Wyngaarden, J. B. Plasma glutamine and oxypurine content in patients with gout. Proc. Soc. exp. Biol. (N. Y.) 1955, 88, 342.

9. Stein, W. H. A chromatographic investigation of the amino acid constituents of normal urine. J. biol. Chem. 1953, 201, 45.

10. Brown, R. H., Duda, G. D., Korkes, S., and Handler, P. A colorimetric micromethod for determination of ammonia; the ammonia content of rat tissues and human plasma. Arch. Biochem. 1957, 66, 301.

11. Schreiner, G. E. Determination of inulin by means of resorcinol. Proc. Soc. exp. Biol. (N. Y.) 1950, 74, 117.

12. Selkurt, E. E. Measurement of renal blood flow. Meth. med. Res., 1949, 1, 191.

13. Rosenthal, T. B. The effect of temperature on the $\mathrm{pH}$ of blood and plasma in vitro. J. biol. Chem. 1948, 173, 25.

14. Van Slyke, D. D., and Neil, J. M. The determination of gases in blood and other solutions by vacuum 
extraction and manometric measurements. J. biol. Chem. 1924, 61, 523.

15. Van Slyke, D. D., and Sendroy, J., Jr. Studies of gas and electrolyte equilibria in blood. XV. Line charts for graphic calculations by the HendersonHasselbalch equation, and for calculating plasma carbon dioxide content from whole blood content. J. biol. Chem. 1928, 79, 781.

16. Hickam, J. B., and Frayser, R. Spectrophotometric determination of blood oxygen. J. biol. Chem. 1949, 180, 457.

17. Wintrobe, M. M. Clinical Hematology, 5th ed. Philadelphia, Lea \& Febiger, 1961.

18. Bradley, S. E., Bradley, G. P., Tyson, C. J., Curry, J. J., and Blake, W. D. Renal function in renal diseases. Amer. J. Med. 1950, 8, 766.
19. Lathem, W., and Benjamin, A. D. Observations on renal protein metabolism. Renal venous amino nitrogen content before and following hemoglobin infusions in dogs. J. exp. Med. 1956, 104, 211.

20. Sartorius, O. W., Roemmelt, J. C., and Pitts, R. F. The renal regulation of acid-base balance in man. IV. The nature of the renal compensations in ammonium chloride acidosis. J. clin. Invest. 1949, 28, 423.

21. Orloff, J., and Berliner, R. W. The mechanism of the excretion of ammonia in the dog. J. clin. Invest. 1956, 35, 223.

22. Shalhoub, R. J., Canessa-Fisher, M., Webber, W. A., Glabman, S., and Pitts, R. F. Sources of urinary ammonia. Fed. Proc. 1961, 20, 415. 